\title{
Design of Very Compact Combline Band-Pass Filter for 5G Applications
}

\author{
Yasir Al-Yasir*, Raed A. Abd-Alhameed*, James M. Noras*, Ahmed M. \\ Abdulkhaleq ${ }^{\dagger}$, Naser Ojaroudi Parchin*, \\ *Bradford University, UK. R.A.A.Abd@bradford.ac.uk, ${ }^{+} S A R A S$ \\ Technology Limited, UK
}

Keywords: Coupled-line, Band-Pass filter, Microwave Filter, Compact size, 5G.

\begin{abstract}
In this paper, a compact microstrip band-pass filter (BPF) covering the 3.4 to $3.8 \mathrm{GHz}$ spectrum bandwidth for $5 \mathrm{G}$ wireless communications is presented. The planar filter uses three resonators, each terminated by a via to hole ground at one end and a capacitor at the other end with $50 \Omega$ transmission line impedances for input and output terminals. The coupling between the lines is adjusted to resonate at the centre frequency with third-order band-pass Butterworth properties. The proposed combline filter is designed on an alumina substrate with a relative dielectric constant of 9.8 and a very small size of $9 \times 5 \times 1.2 \mathrm{~mm}^{3}$. The proposed filter is simulated and optimized using CST microwave studio software.
\end{abstract}

\section{Introduction}

RF noise is an increasingly serious issue in modern wireless communication applications such as $5 \mathrm{G}$ and wide-band radar systems [1]. Microstrip band-pass filters are commonly used to filter noise signals and unwanted frequencies in wireless communication applications [2], particularly in RF and microwave applications due to their effective rejection of spurious frequencies. Nowadays, $5 \mathrm{G}$ wireless communication technology is being considered for use in $700 \mathrm{MHz}, 3.6 \mathrm{GHz}$ and $26 \mathrm{GHz}$ bands [3]. Band-pass filters are useful units in many $5 \mathrm{G}$ systems for rejecting unwanted signals. In addition, there are particular requirements for band-pass filters in such systems [4, 5]. A band-pass filter contains a number of coupled resonators, and the dimensions of the distributed elements and the number of resonators proposed defines the filter characteristics. Consequently, most microstrip filter miniaturization techniques seek to minimize one or other of these quantities.

A variety of structures and methods have been proposed for microstrip line filters such as combline, hairpin, parallel- coupled line, step impedance, and stub impedance [6-13]. A Chebyshev microstrip filter is proposed for a 2.40 to $2.48 \mathrm{GHz}$ passband with $0.5 \mathrm{~dB}$ ripple. Insertion loss and return loss are to be $\leq 1 \mathrm{~dB}$ and $>15 \mathrm{~dB}$ respectively [6]. In [8], a compact planar band-pass filter (BPF) was designed by using a new microstrip coupled line technique. Two sections of three parallel-coupled lines, a quarter wavelength long, was employed to construct a filter with a centre frequency of about 3.0 GHz. The lines are 
separated by non-uniform line elements, and the filter's size was $20.9 \times 7.3 \mathrm{~mm}^{2}$. Another technique employed low temperature co-fired ceramic (LTCC) [9], whose implementation is being made more feasible by means of reliable electromagnetic analysis, making possible filter structures of minimum physical size. Planar hairpin resonators can be used to implement a physically small band-pass filter. The design of the hairpin filter uses a varied coupling effect across the hairpin shape with T-feeders [10]. The measured operation frequency is shifted down by approximately $0.2 \mathrm{GHz}$ from the simulated $5.8 \mathrm{GHz}$ centre frequency required by RFID applications.

The resonator size is approximately $26.3 \times 12.2 \mathrm{~mm}^{2}$. Combline filter design, with the advantages of small physical size and low loss, are now commonly used in many applications [11, 12]. In [11], a new improved combline band-pass filter is reported with multiple transmission zeros, two poles, and an area of $27.6 \times 5 \mathrm{~mm}^{2}$. The filter's centre frequency is $1.43 \mathrm{GHz}$ with a $3 \mathrm{~dB}$ fractional bandwidth of about $11.51 \%$, insertion loss around $2.781 \mathrm{~dB}$ and passband return loss around $18.1 \mathrm{~dB}$. An enhanced combline bandpass with stepped- impedance containing an array of SIRs is designed and explained in [12]. The design has the merit of no lumped elements and few via-hole grounds which is recommended for multilayer microstrip line implementation. For the fourth- order design, return loss and the insertion loss better than $17 \mathrm{~dB}$ and $2.0 \mathrm{~dB}$ respectively, all by using a planar with $13 \times 9 \mathrm{~mm} 2$ area.

In this article, a physically small third-order microstrip combline BPF is designed using CST microwave studio software tools to cover the frequency band 3.4 to $3.8 \mathrm{GHz}$, suitable for $5 \mathrm{G}$ wireless communication applications. It uses an alumina substrate. Very good insertion loss of $0.1 \mathrm{~dB}$ has been achieved. Furthermore, it is significant that this design can be easily developed to handle and permit reconfigurability $[13,14]$ and can be easily integrated with antenna design [15], to create the so-called "filtenna" [16]. The filter design and its performance are presented and discussed in the next coming sections.

\section{Filter Design and Configuration}

The filter design procedure starts with a Butterworth low-pass filter prototype that is normalized in terms of impedance and frequency. Then, transformations are applied to convert the prototype design (LPF) to the desired frequency range (BPF). These two steps lead to circuits of lumped elements (capacitors and inductors). Finally, the Richards' transformation is used to convert the lumped elements into a microstrip transmission line [2].

\subsection{Butterworth Low-Pass Filter Prototype}

This section discusses the design of a 3-pole Butterworth low- pass prototype filter with centre frequency $3.6 \mathrm{GHz}$ and fractional bandwidth $11 \%$ and low ripple insertion loss. Figure 1 shows a ladder type of the low-pass prototype with low-pass parameters gi for $i=0$ to $\mathrm{n}+1$. 


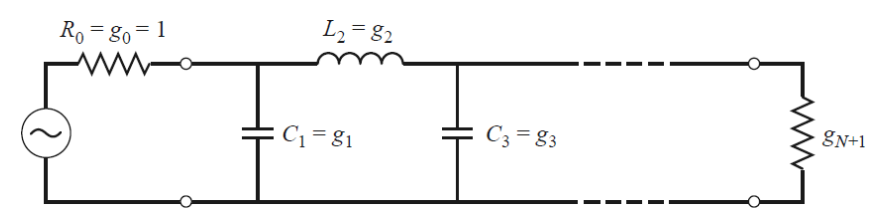

Figure 1: Low-pass filter form with degree $n$.

The element values of $g_{i}$ in Figure 1 can be computed by using the low-pass Butterworth filter prototype which gives: $\mathrm{g}_{0}=\mathrm{g}_{4}=1.0 \mathrm{mhos}, \mathrm{g}_{1}=\mathrm{g}_{3}=1.0 \mathrm{H}$ and $\mathrm{g}_{2}=2.0 \mathrm{~F}$ for $\Omega_{\mathrm{c}}=1.0 \mathrm{rad} / \mathrm{s}$, from [2].

\subsection{Frequency and Element Transformations (Band-Pass Filter Design)}

To obtain the band-pass filter design with element values from the low-pass prototype filter (which has a normalized source resistance/conductance $\mathrm{g} 0=1$ and a cut-off frequency $\Omega \mathrm{c}$ $=1.0 \mathrm{rad} / \mathrm{s}$ ), frequency and element transformations can be applied. The frequency mapping affects the reactive values but has no effect on the resistive values. The impedance scaling factor is $\gamma 0=50$. The angular cut-off frequency $2 \pi \times$

$3.6 \times 10^{9} \mathrm{rad} / \mathrm{s}$. According to [2], we find L1 $=\mathrm{L} 3=20 \mathrm{nH}, \mathrm{L} 2$

$=0.12 \mathrm{nH}, \mathrm{C} 1=\mathrm{C} 3=0.09 \mathrm{Pf}$ and $\mathrm{C} 2=16 \mathrm{pF}$. The band-pass filter obtained is shown in Figure 2, which is based on the 3-pole Butterworth low-pass prototype explained previously. The characteristics of the lumped-element BPF operating at

3.6 GHz are plotted and shown in Figure 3.

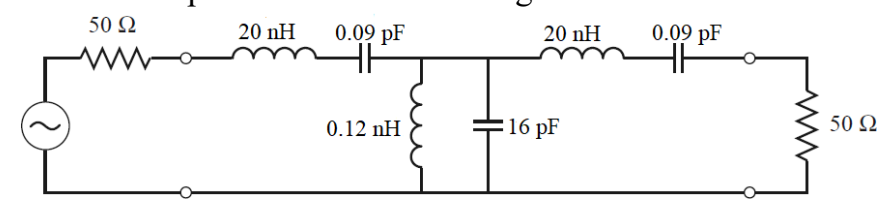

Figure 2: Band-pass filter based on the transformation.

\subsection{Implementation of the Combline Band-Pass Filter}

Richards' transformations [2] are used to allow the inductors and capacitors of the lumped element filter designed in the previous sections to be replaced by open circuit and short circuit stubs of transmission line, as shown in Figure 4. The electrical lengths of all the stubs are the same $(\lambda / 8$ at $\omega c)$.

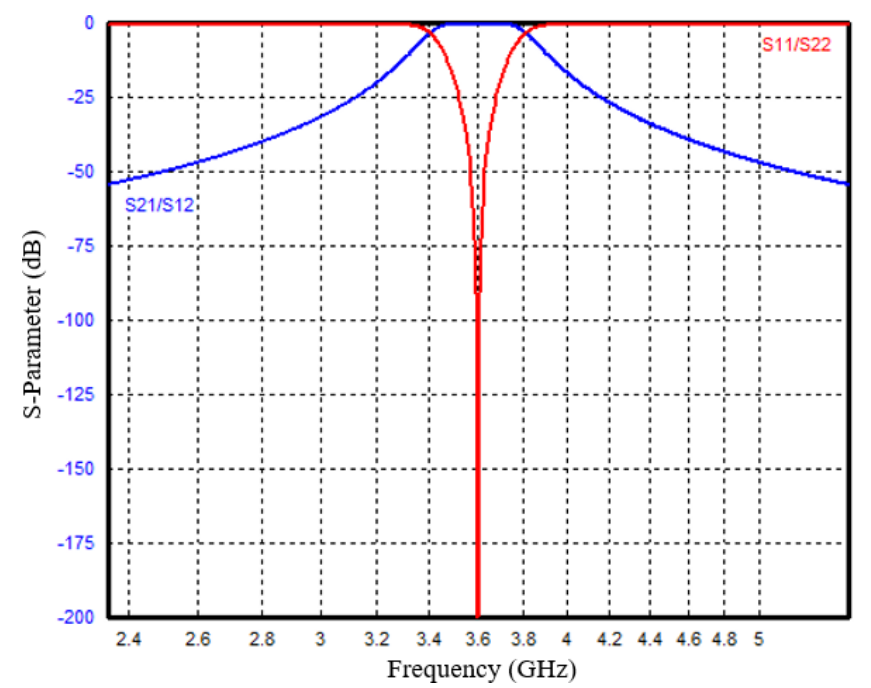

Figure 3: $\mathrm{S}_{21}$ and $\mathrm{S}_{11}$ of $3.6 \mathrm{GHz}$ lumped-element band-pass filter. 

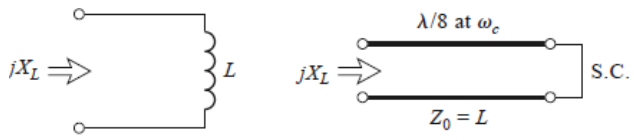

(a)

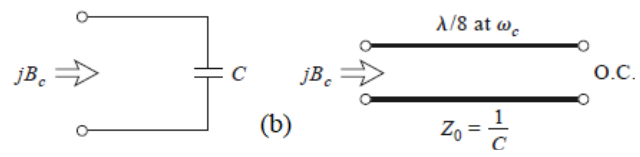

Figure 4: Lumped and distributed element correspondence under Richards' transformation.

The combline filter consists of equal length multi-wire lines with coupling constrained between the adjacent lines. The lines are short-circuited to ground at one end, while the other ends are terminated with lumped capacitors. At the operation frequency of the filter, the lines are markedly less than $\lambda / 8$. The optimized dimensions are achieved by using the built-in optimizer embedded with the CST software and they are summarized in Table 1. By using these optimized dimensions, the BPF schematics are transformed to the geometry presented in Figure 5. CST microwave studio software is used to develop the band-pass filter design. The substrate has a relative dielectric constant $\varepsilon_{r}=9.8$ with thickness $\mathrm{h}=1.2 \mathrm{~mm}$. The filter design has a characteristic impedance of a microstrip line of $\mathrm{Zc}=50 \Omega$. The thickness of the copper is $(\mathrm{t}$ $=0.00254 \mathrm{~mm})$ with dielectric loss tangent $(\tan \delta=0.0001)$.

\begin{tabular}{|c|c|c|c|c|}
\hline $\mathrm{W}_{\text {sub }}$ & $\mathrm{L}_{\text {sub }}$ & $\mathrm{W}$ & $\mathrm{L}_{1}$ & $\mathrm{~L}_{2}$ \\
\hline 9 & 5 & 1.56 & 1.23 & 3.26 \\
\hline
\end{tabular}

Table 1: Optimized dimensions in $\mathrm{mm}$ of the proposed combline BPF.

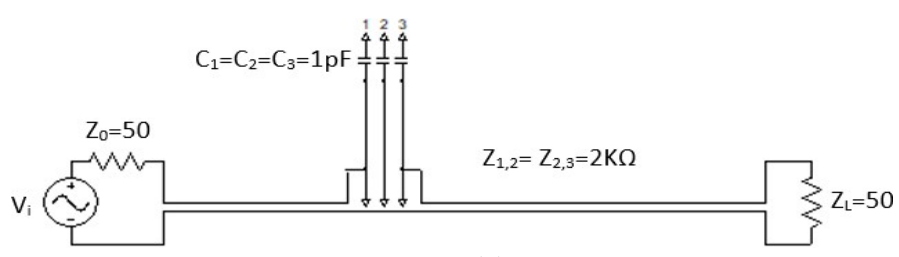

(a)

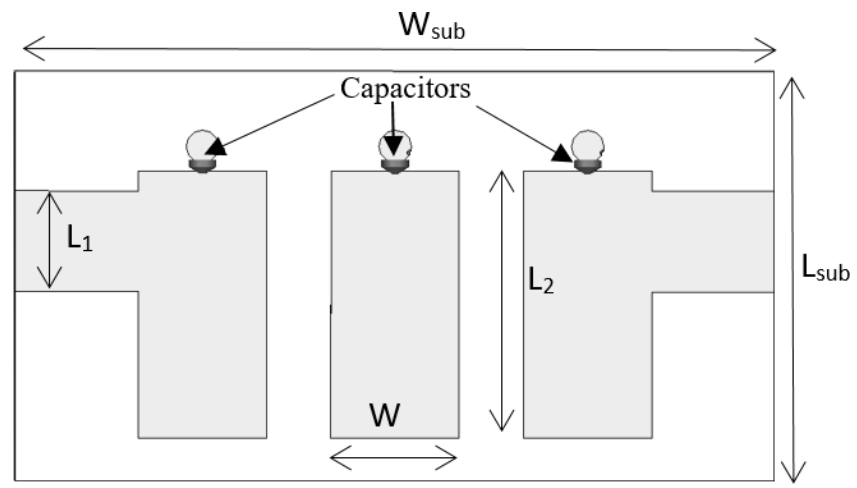

(b) 


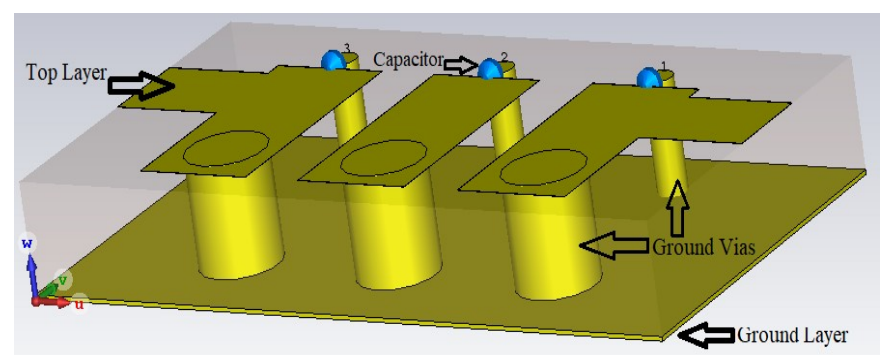

(c)

Figure 5: The proposed combline BPF filter. (a) Layout of the third-order design. (B) 2D configuration. (c) 3D configuration

\section{Return/Insertion Loss Characteristics of the Proposed Filter}

The characteristics of the proposed combline BPF are plotted and shown in Figure 6.

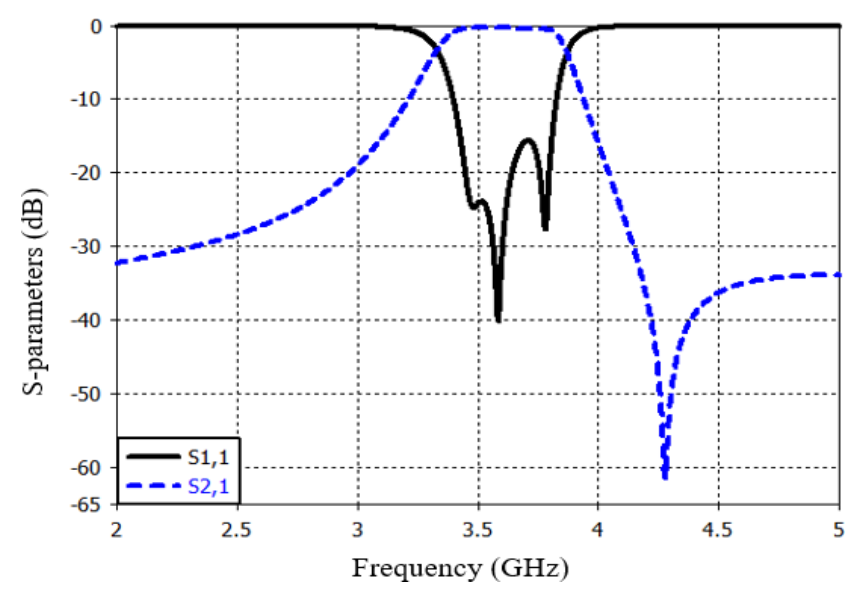

Figure 6: Return/Insertion loss characteristics of the third- order combline BPF.

The BPF has insertion losses of approximately $0.1 \mathrm{~dB}$ across the pass-band while the pass-band return loss was better than $15 \mathrm{~dB}$ across the required band 3.4 to $3.8 \mathrm{GHz}$. Furthermore, and to improve the selectivity of the proposed design, one transmission zero has been successfully introduced in the higher stop-band frequency. The performance characteristics are achieved by using the CST software, and the results of the parameters are been shown.

\section{Conclusion}

Small and compact size, a third-order band-pass filter is designed and optimized using the combline technique with the aid of CST software. The first step of design starts with lumped-elements (capacitors and inductors), then transformation and scaling achieves the desired microstrip line filter. The compact size with very low insertion loss of the resultant designed filter can be recommended as a good candidate for possible use in future applications of $5 \mathrm{G}$ spectrum. 


\section{Acknowledgements}

This work is partially supported by innovation programme under grant agreement H2020MSCA-ITN-2016 SECRET- 722424 and the financial support from the UK Engineering and Physical Sciences Research Council (EPSRC) under grant EP/E022936/1.

\section{References}

[1] A. Hussaini, Y. Al-Yasir, k. Voudouris, B. Mohammed, R. Abd-Alhameed, H. Mohammed, I. Elfergani, A. Abdullah, D. Makris, J. Rodriguez, J. Noras, C. Nche, and M. Fonkam, Green Flexible RF for 5G. Fundamentals of $5 \mathrm{G}$ Mobile Networks. pp. 241-272, John Wiley and Sons, (2015).

[2] J.-S. G. Hong and M. J. Lancaster, Microstrip Filters for RF/Microwave, vol. 167, John Wiley and Sons, (2004).

[3] "Ofcom," 8 February 2017. [Online]. Available: https://www.ofcom.org.uk/.

[4] J. S. Jeon, S. T. Kang and H. S. Kim. "GAoptimized compact broadband CRLH band-pass filter using stub- inserted interdigital coupled lines" Journal of Electromagnetic Engineering and Science, vol. 15, no. 1, pp. 31-36, (2015).

[5] C. X. Wang, F. Haider, X. Gao, X. H. You, Y. Yang, D. Yuan, H. Aggoune, H. Haas, S. Fletcher avd E. Hepsaydir. "Cellular architecture and key technologies for $5 \mathrm{G}$ wireless communication networks" IEEE Commun. Mag., vol. 52, no. 2, pp. 122-130, (2014).

[6] S. Srivastava, R. K. Manjunath and P. Shanthi. "Design, simulation and fabrication of a microstrip bandpass filter" International Journal of Science and Engineering Applications, vol. 3, no. 5, pp.1-4, (2014).

[7] J. Rajendran, R. Peter, and K. P. Soman. "Design and optimization of band pass filter for software defined radio telescope" International Journal of Information and Electronics Engineering, vol. 2, no. 4, pp. 694-651, (2012).

[8] H. N. Shaman. "New S-band bandpass filter (BPF) with wideband passband for wireless communication systems" IEEE Microwave Component Letter, vo. 22, no. 5 pp. 242-244, (2012). 
[9] M. R. Saad, Z. Ambak, R. Alias and A. Ibrahim. "Designing $5 \mathrm{GHz}$ microstrip coupled line bandpass filter using LTCC technology" in Proc. IEEE International Conference on Electronic Design, pp. 1-4, Penang, (2008).

[10 R. K. Maharjan, and N. Y. Kim. "Microstrip

] bandpass filters using window hairpin resonator and T-feeder coupling lines" Arabian Journal for Science and Engineering, vol 39, no. 5, pp. 3989-3997, (2014).

[11 S.-C. Lin, C.-H. Wang, Y.-W. Chen and C. H.

] Chen. "Improved Combline Bandpass Filter with Multiple Transmission Zeros" 2007 AsiaPacific Microwave Conference, pp. 1-4, Bangkok, (2007).

[12 Y.-M. Chen, S.-F. Chang, C.-C. Chang, and T.-

] J. Hung. "Design of stepped-impedance combline bandpass filters with symmetric insertion-loss response and wide stopband range" IEEE Transaction on Microwave Theory Technology, vol. 55, no. 10, pp. 2191-2199, Oct. (2007).

[13 D. Psychogiou, R. Gómez-García, D. Peroulis.

] "RF Wide-Band Bandpass Filter With Dynamic In-Band Multi-Interference Suppression Capability" IEEE Transactions on Circuits and Systems II: Express Briefs, vol. 65, no. 7, pp. 898-902, (2018).

[14 M. Yuceer. "A reconfigurable microwave

] combline filter" IEEE Transactions on Circuits and Systems II, Express Briefs, vol. 63, no. 1, pp. 84-88, Jan. (2016).

[15 Y. Abdulraheem, A. Abdullah, H. Mohammed,

] R. Abd- Alhameed and J. Noras. "Design of Frequency- reconfigurable Multiband Compact Antenna using two PIN diodes for WLAN/WiMAX Applications" IET Microwaves, Antennas and Propagation, vol. 11, no. 8, pp. 1098-1105, (2017).

[16 H. A. Atallah, A.-R. Abdul Rahman, K.

] Yoshitomi and

P. Pokharel. "Compact frequency reconfigurable filtennas using varactor loaded tshaped and h-shaped resonators for cognitive radio applications," IET

Microwaves, Antennas and Propagation, vol. 10, no. 9, pp. 991-1001, (2016). 
